\title{
Lack of knowledge and false perception on space spraying against dengue in endemic area
}

\author{
Siwi Pramatama Mars Wijayanti ${ }^{1}$, Devi Octaviana ${ }^{2}$, Arnika Dwi Asti ${ }^{3}$ \\ ${ }^{1,2}$ Public Health Department, Faculty of Health Sciences, Jenderal Soedirman University, Indonesia \\ ${ }^{3}$ Faculty of Nursing, STIKES Muhamadiyah Gombong, Indonesia
}

\section{Article Info \\ Article history: \\ Received Jul 20, 2020 \\ Revised Sep 3, 2020 \\ Accepted Sep 15, 2020}

\section{Keywords:}

Community

Dengue

Fogging

Knowledge

Outdoor spatial spraying

\begin{abstract}
Space spraying is still considered as the most powerful method to control the spread of dengue virus transmission, particularly in an emergency such as an outbreak. However, there is still limited information about how the knowledge and perception of people about space spraying against dengue. This study aimed to assess knowledge and community perception of space spraying against dengue in an endemic area. This study was a descriptive cross-sectional study, involved 273 respondents in three endemic areas in Kebumen Regency, Central Java, Indonesia. Structured questionnaires about knowledge and perception of space spraying were administered to the respondents. The $41.4 \%$ of respondents had poor knowledge about space spraying, and $42.1 \%$ had a negative perspective about space spaying. Only $15.4 \%$ of respondents aware that space spraying applications must be carried out based on several criteria and procedures. Most of them assumed that space spraying can be applied anytime and feel secure when space spraying was applied in their near area. Lack of knowledge and false security on space spraying applications could make people less active to conduct routine practice of mosquito breeding site eradication. It is important to enhance community knowledge and perception of space spraying, so they could understand that space spraying application only for emergencies and routine mosquito breeding site prevention must be carried out regularly.
\end{abstract}

This is an open access article under the CC BY-SA license.

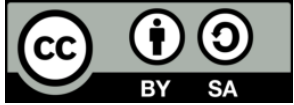

\section{Corresponding Author:}

Siwi Pramatama Mars Wijayanti, Department of Public Health,

Faculty of Health Sciences, Jenderal Soedirman University,

Jl. dr. Soeparno, Karangwangkal, Purwokerto Utara, Indonesia.

Email: siwimars@gmail.com

\section{INTRODUCTION}

Dengue virus (DENV) infection remains an important health problem, particularly in tropical areas. This disease was caused by Dengue Virus, the genus of Flavivirus, family Flaviviridae which consists of five antigenically distinct and medically relevant serotypes, (DENV1, 2, 3, 4 and 5) [1, 2]. It is transmitted to humans by the bite of infected mosquitoes, Aedes aegypti as primary vectors, and Aedes albopictus mosquitoes as the secondary vector [3]. The clinical manifestations could vary from asymptomatic to severe illness such as dengue haemorrhagic fever (DHF) and dengue shock syndrome (DSS) [4]. Recent studies have estimated approximately four billion people in over 120 countries at risk of dengue, with 50-100 million annual symptomatic cases, mostly occurring in the Asia-Pacific region [5, 6]. Indonesia has experienced dengue infection since 1968 in the cities of Jakarta (capital of Indonesia) and Surabaya (East Java). Since then, dengue continues to spread throughout the provinces, and frequent epidemics occurred in many areas in Indonesia [7]. Annually, Java Island 
reported the largest total number of cases of dengue hemorrhagic fever. There has been a dramatic increase in DHF Incidence Rate/IR in Indonesia over the past five decades, with a cyclic pattern peaking approximately every six to Eight years, while the annual case fatality rate (CFR) has declined over time. Roughly 65.6 thousand dengue cases were reported in Indonesia in 2018 [8]. The spread of dengue is usually influenced by demographic, socioeconomic factors, temperature, humidity, rainfall, and mosquito density $[9,10]$.

Dengue viruses circulate mainly between human and vector mosquitoes, therefore, mosquito vector control are the primary dengue prevention effort, currently. Various methods of prevention and control such as biological, mechanical, genetic, chemical, and integrated control have been carried out [11]. One of the prevention methods in the community is to eradicate mosquito nests which are draining water reservoirs that have the potential to become mosquito breeding sites, closing water reservoirs, and burying or recycling used goods around the house so as not to become potential breeding places for mosquitoes [12]. While in the event of an outbreak, space spraying of often familiar as "fogging" is still considered as the most powerful method to control the spread of dengue virus transmission [13]. Fogging is an effort to stop the chain of transmission of dengue only in emergencies to suppress an ongoing epidemic by spraying chemical insecticides in the form of aerosols. Generally, the pesticides used are Pyrethroids. Insecticide sprayed around the house will kill only adult mosquitoes, while the mosquito's eggs and larvae remain alive. Space spraying performance depends on many factors, such as the method of release (aircraft, vehicle, hand-held equipment); fog forms (cold or thermal); droplet size, application rate, environment conditions; building structures, design, and penetration of space sprays; target area size; terrain and accessibility; and the peak flight time of mosquitoes [14]. While space spraying is widely used by national dengue control programs, there is no clear evidence that peridomestic space spraying is recommended as a single, successful control action [15]. The application of space spraying must be carried out with certain criteria, such as if there is a report of dengue patients, and after epidemiological investigations found other dengue patients ( 1 or more) or found three or more dengue suspect and found larvae $(\geq 5 \%)$ from the house/building being examined [16].

However, the arise concern that space spraying applications could lead to false security effects of people in the treated area. False security effects could cause a decrease in participation of people to do regular dengue prevention such as mosquito breeding site eradication [17]. This could be due to a lack of public knowledge about fogging, where they consider that after fogging the area will be safe and do not need to make preventative efforts. People also tend to ask for space spraying application more often, without considering the criteria. It is important to know that the use of insecticide could affect several negative effects such as environmental, health impact, and insecticide resistance [18]. Space spraying against dengue was applied to stop dengue transmission in several areas in Indonesia, however, how the knowledge and perception of community to space spraying implementation is still limited. This present study aims to assess the knowledge and perception of respondents in space spraying treated area, Gombong Sub-district, Kebumen Regency, Central Java Indonesia. Gombong sub-district in Kebumen Regency is one of the dengue endemic areas. The number of reported cases of dengue increased from 129 in 2014 (Incidence Rate 10.92) to 215 in 2015 (IR 18.1 per 100,000 population). The highest number of cases of dengue occurred primarily at the Gombong II Health Center particularly in Gombong Village, Semanding, and Kalitengah. The number of cases that occurred in the three villages during 2016 was 27, 32 and 24 cases. Interventions using space spraying have been carried out to stop the spread of dengue in these areas. Information from this research is expected to provide information on the knowledge and public perception of space spraying so that it can be a useful input for health institutions.

\section{RESEARCH METHOD}

\subsection{Study design and sampling}

This was a descriptive study with a cross-sectional design, conducted in Gombong Sub District, Kebumen Regency, Central Java, Indonesia on March-October 2017. Three selected villages treated with space spraying in three consecutive years were included in this study (Semanding, Gombong, and Kali Tengah). The areas of study were determined based on areas treated by space spraying to control dengue spread. Information about space spraying history obtained from Section of Infectious disease prevention, Kebumen Regency Health Officer. The study was distributed in three villages as the study site; 300 respondents were identified (100 people in each village). However, only 273 complete data could be analyzed after the cleaning of the data.

\subsection{Data collection}

Knowledge and perception were assessed by structured questionnaires. Perception variables were measured by Likert scale. The space spraying questionnaire included questions to explore whether respondents knew about fogging criteria and their perceptions of security when this method was implemented in their village. 


\subsection{Ovitrap Installation}

Ovitraps were installed in 100 houses per village studied (Semanding, Gombong, and Kalitengah villages). Ovitrap is made from $250 \mathrm{ml}$ plastic containers painted black on the outside. During installation, the container is filled 1/3 with water and the paper filter is placed around the surface wall in the container to place the eggs for the mosquitoes. After 6 days of installation, the ovitrap is taken and then the egg is counted. The ovitrap index was calculated based on the percentage of ovitrap positive eggs per the total number of ovitrap observed.

\subsection{Data analysis}

Univariate analysis was used to describe the knowledge and perception of respondents. For knowledge, we used 5 cut-off points and 21 cut-off points for perception about space spraying.

\section{RESULTS AND DISCUSSION}

A structured questionnaire was administered to 273 of respondents in three villages in Gombong sub-district, Kebumen Regency. Most of the respondents were women $(79.49 \%)$, had the status of being housewives, because the research was conducted during the daytime so that they were mostly at home. $45.05 \%$ of respondents aged 36-50 years with $38.46 \%$ of respondents completed junior high school. Details of the characteristics of the respondents are shown in Table 1. Based on data analysis of the questionnaire, we categorized the knowledge and perception of the respondent about space spraying in Table 2.

Table 1. Characterictic of respondents

\begin{tabular}{lrr}
\hline Characteristic & $\mathrm{n}$ & $\%$ \\
\hline Gender & & \\
Male & 56 & 20.51 \\
Female & 217 & 79.49 \\
Age groups (years old) & & \\
17-35 & 98 & 35.90 \\
$36-50$ & 123 & 45.05 \\
$>50$ & 52 & 19.05 \\
Level of education & & \\
$\quad$ Uneducated & 5 & 1.83 \\
primary school & 93 & 34.07 \\
Junior high school & 105 & 38.46 \\
Senior high school & 69 & 25.27 \\
University & 1 & 0.37 \\
Employment & & \\
Housewives & 161 & 58.97 \\
Entrepreneur & 45 & 16.48 \\
Farmer & 34 & 12.45 \\
Employee & 33 & 12.09 \\
\hline
\end{tabular}

Table 2. Knowledge and perception of respondents about space spraying

\begin{tabular}{cccc}
\hline \multicolumn{2}{c}{ Variables } & $\mathrm{n}$ & $\%$ \\
\hline Knowledge & Good & 160 & 58.6 \\
& Poor & 113 & 41.4 \\
Perception & Good & 158 & 57.9 \\
& Poor & 115 & 42.1 \\
\hline
\end{tabular}

This study highlighted that even though respondents came from the area that was treated with space spraying, however, there was $41.4 \%$ of respondents still had poor knowledge about space spraying. Based on the detail of questions, we found that only $15.4 \%$ of respondents answered correctly that space spraying must be carried out at certain times and criteria, while most of them still consider if fogging can be carried out at any time as shown in Table 3. Space spraying/fogging is a procedure that is used only during an epidemic and must be performed when the required conditions are met. The problem such as insecticidal resistance to mosquitoes that have arisen in certain areas can also be caused by the introduction of space spraying that is not in line with the guidelines. Spraying the insecticide too frequently could lead mosquitoes to become resistant to the insecticide, rendering it ineffective [19]. 
This study also reported that $8.1 \%$ of respondents assumed that space spraying is more effective than regular dengue prevention. This could discourage respondents from conducting routine dengue prevention. In Indonesia, there is a program which applied to eradicate the mosquito's breeding place by practicing the 3M Plus approach. The basic action of 3M Plus consists of "Menguras/Drain" or to drain water reservoirs such as bathtubs, buckets of water, drinking water reservoirs, storage in refrigerators, and so on. Secondly, "Menutup/Close" or to cover items like drums and water storage cistern, and thirdly, "mengubur/bury" to bury or utilize/recycle used goods that can be potentially used by the dengue mosquitoes in laying their eggs. While "Plus" includes all forms of dengue prevention, such as larvacide application, using mosquito repellents, keeping fish predators, or wearing a long shirt to minimize from mosquito bites [11]. The community should aware that they need to conduct these preventive efforts regularly, even though space spraying was applied in their area. Details of the results of the questionnaire related to knowledge of space spraying can be seen in Table 3. We also assess the detail of perception statements about space spraying, which showed in Table 4.

Table 3. Detail of question of knowledge of space spraying

\begin{tabular}{|c|c|c|c|}
\hline & \multirow{2}{*}{ Questions of knowledge of space spraying } & \multicolumn{2}{|c|}{ Right answers } \\
\hline & & $\mathrm{n}$ & $\%$ \\
\hline 1 & Fogging is a program of controlling mosquitoes of dengue with a smoke spray containing insecticide & 245 & 89.7 \\
\hline 2 & Fogging is usually carried out only if there is a case of dengue that occurs in a village. & 234 & 85.7 \\
\hline 3 & Fogging is only killing adult mosquito, while eggs and larvae remain alive. & 167 & 61.2 \\
\hline 4 & After fogging was carried out, dengue disease will disappear $*$ & 121 & 44.3 \\
\hline 5 & $\begin{array}{l}\text { Although fogging has been done, the community must keep eradicating mosquito nests by closing water } \\
\text { reservoirs, draining tubs, and burying used goods. }\end{array}$ & 267 & 97.8 \\
\hline 6 & Fogging can be done anytime $*$ & 42 & 15.4 \\
\hline 7 & Fogging is more effective for controlling dengue than mosquito breeding site eradication $*$ & 104 & 38.1 \\
\hline \multirow[t]{2}{*}{8} & Fogging smoke is harmless if inhaled & 146 & 53.5 \\
\hline & Number of respondents & 273 & 100.0 \\
\hline
\end{tabular}

Table 4. Detail of perception of respondents about space spraying

\begin{tabular}{|c|c|c|c|c|}
\hline \multirow{2}{*}{ Statements } & \multicolumn{4}{|c|}{ Perceptions } \\
\hline & SD & $\mathrm{D}$ & A & SA \\
\hline 1. I feel safer from dengue when space spraying was applied in my area. & 19.4 & 1.1 & 12.1 & 67.4 \\
\hline $\begin{array}{l}\text { 2. I feel that fogging/space spraying is more effective in controlling dengue than eradicating mosquito } \\
\text { breeding sites such as closing water reservoirs, draining baths and burying used goods * }\end{array}$ & 3.3 & 37.4 & 52.4 & 7 \\
\hline $\begin{array}{l}\text { 3. I understand that fogging must be done according to the particular criteria and the procedure must be } \\
\text { correct. }\end{array}$ & .7 & 3.3 & 76.2 & 19.8 \\
\hline 4. I consider that fogging can also endanger health because the smoke contains insecticides/poisons & 2.2 & 17.9 & 71.4 & 8.4 \\
\hline 5. Prevention and control of dengue disease is the duty of the government, not the community.* & 7.7 & 49.8 & 37.7 & 4.8 \\
\hline 6. I don't feel disturbed if space spraying was applied in my area & 1.5 & 12.5 & 76.9 & 9.2 \\
\hline $\begin{array}{l}\text { 7. If fogging has been carried out, there is no need to take precautions such as closing water reservoirs, } \\
\text { draining baths and burying used goods } *\end{array}$ & 19 & 53.8 & 24.2 & 2.9 \\
\hline 8. I support it if fogging is only done when needed, because fogging costs a lot. & 6.2 & 42.5 & 49.5 & 1.8 \\
\hline
\end{tabular}

* $\mathrm{SD}=$ strongly disagree, $\mathrm{D}=$ disagree, $\mathrm{A}=$ agree, $\mathrm{SA}=$ strongly agree

In this report, only 61.2 percent of respondents who know that space spraying kills adult mosquitoes only, while eggs and larvae remain alive. In space spraying application, the spray from the mixture of insecticide and water will drift throughout the treated area, only targeted adult mosquitoes, do not target the eggs larva or pupae [20]. This result of the study is risky because of this lack of knowledge could make them feel false protection against the danger of dengue transmission. This can make people ignorant of prevention efforts such as eradicating mosquito breeding sites that must be carried out regularly. The lack of knowledge, false perception, and low participation of the community is a challenge for the public health sector to encourage people to conduct a routine 3M Plus program. Several studies showed a correlation between good knowledge and perception which translates into practice [21, 22]. We also found that $42.1 \%$ of respondents had a poor perception of space spraying. The false security of space spraying application was also observed here, where $67.4 \%$ of respondents feel safer when space spraying was applied in their area. Besides, $37.7 \%$ of respondents also assumed that prevention and control of dengue disease is the duty of the government, not the community. Whereas community engagement is the key to the success of dengue vector control initiatives as it needs effective community-based preventive efforts. Several previous studies have suggested similar things about the importance of community involvement in preventing and controlling dengue. A robust and improved dengue management approach focused on community participation has a huge impact on dengue prevention [23, 24]. 
Lack of knowledge and awareness of respondents concerning space spraying is likely because of their level of education, much of which is still in the field of primary to secondary education. Several studies note a connection between one's knowledge and education. Higher education individuals will have better knowledge and will have the ability to better understand and received information properly. Education can increase health awareness either directly, e.g. through school-administered health instruction, or indirectly by increasing a person's capacity to absorb health information $[25,26]$. Many respondents are also housewives whose exposure to media information may be limited. The role of exposure to information media is very important in directing health behavior in society [27]. Adding information support to this study, we found that the area of study was categorized in level $2(5 \% \leq$ O.I. $<20 \%)$, and level $33(20 \% \leq$ O.I. $<40 \%$ ) as shown in Figure 1. This data showed that the number of eggs in the area of study remains medium density, indicated that people may do not do routine $3 \mathrm{M}$ plus. Based on the Food and Environmental Hygiene Department, Hong Kong, the community in level 2 advised to check and eliminate mosquito breeding sites at least once a week. As for level 3, it is recommended to make additional efforts in addition to efforts to inspect and eliminate breeding sites that are conducted once a week [28].

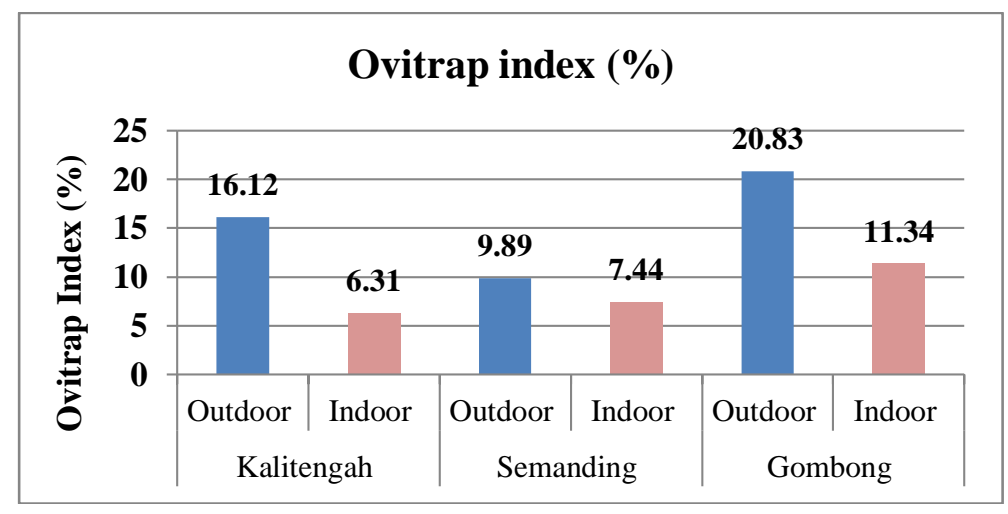

Figure 1. Percentage of ovitrap index in the area of study

Based on Figure 1, it is seen that the highest ovitrap index is in Gombong Village in the outdoor position (20.83\%), with the indoor position being the highest among the other three villages (11.34\%). While the lowest OI for outdoor positions is in Semanding Village (9.89\%), and the lowest indoor position is positions compared to indoor. Based on the OI level, the Kalitengah and Semanding Villages categorized as Level $2(5 \% \leq$ O.I. $<20 \%)$, while Gombong as Level $3(20 \% \leq$ O.I. $<40 \%)$. The findings of the ovitrap index support the likelihood of false protection in communities where space spraying has taken place. The determination of medium-criteria mosquito eggs shows that there are still many mosquito populations in the region. There is also a possibility of dengue transmission because of the mosquito vector that is still in medium density. Several previous studies have shown a correlation between mosquito population density and dengue cases [29, 30]. This result supported the need for awareness of people in the treated area of space, that they still should conduct routine mosquito breeding site eradication in their area to reduce mosquito population [31]. Another study also stated that space spraying in the study area was inadequate and often failed to prevent secondary cases of DF/DHF [32].

\section{CONCLUSION}

The findings of this study highlighted the low level of awareness and false assumptions about space spraying that could contribute to the emergence of false security in the community. The ovitrap index in the study area also indicates the medium level showing the possibility of dengue transmission. It should be a challenge for health organizations to make a number of efforts to improve awareness and understanding of space spraying in the community. Proper and accurate awareness will ensure that the community remains inspired to actively engage in efforts to prevent dengue by carrying regular mosquito breeding programs. Health institutions are expected to provide counseling or various media information to increase public knowledge and appropriate perceptions of space spraying. Further studies can be carried out by exploring related sources of information accessed by the public. Analytical studies to determine which variables affect knowledge and awareness regarding space spraying in the community are also interested to be carried out in the future. 


\section{ACKNOWLEDGEMENTS}

We acknowledge the student of the Department of Public Health, Faculty of Health Sciences, Jenderal Soedirman University and Faculty of Nursing, STIKES Muhamadiyah Gombong for their help on field data collection.

\section{REFERENCES}

[1] Mustafa MS., Rasotgi V., Jain S., Gupta V., "Discovery of fifth serotype of dengue virus (DENV-5): A new public health dilemma in dengue control," Medical Journal, Armed Forces India, vol. 71, no.1, pp. 67-70, 2015.

[2] Yung C-F, Lee K-S, Thein T-L, Tan L-K, Gan VC, et al., "Dengue Serotype-Specific Differences in Clinical Manifestation, Laboratory Parameters and Risk of Severe Disease in Adults, Singapore," The American Journal of Tropical Medicine and Hygiene, vol. 92, no. 5, pp. 999-1005, 2015.

[3] Higa Y., "Dengue Vectors and their Spatial Distribution," Tropical Medicine and Health, vol. 39, no. 4 Suppl, pp. 17-27, 2011.

[4] Kalayanarooj S., "Clinical Manifestations and Management of Dengue/DHF/DSS," Tropical Medicine and Health, vol. 39, no. 4 Suppl, pp. 83-87, 2011.

[5] Stanaway JD, Shepard DS, Undurraga EA, Halasa YA, Coffeng LE, et al., "The global burden of dengue: an analysis from the Global Burden of Disease Study 2013," Lancet Infect Dis., vol. 16, no. 6, pp. 712-723, 2016.

[6] Bhatt S, Gething PW, Brady OJ, Messina JP, Farlow AW, et al. "The global distribution and burden of dengue," Nature, vol. 496, no. 7446, pp. 504-7, 2013.

[7] Karyanti MR, Uiterwaal CS, Kusriastuti R., Hadinegoro SR, Rovers MM, et al., "The changing incidence of dengue haemorrhagic fever in Indonesia: a 45-year registry-based analysis," BMC Infect Dis., vol. 14, no. 1, pp. 412, 2014

[8] Harapan H., Michie A., Mudatsir M., Sasmono RT, Imrie A., "Epidemiology of dengue hemorrhagic fever in Indonesia: analysis of five decades data from the National Disease Surveillance," BMC Research Notes, vol. 12, no. 1, p. 350, 2019.

[9] Wijayanti SPM, Porphyre T, Chase-Topping M, Rainey SM, McFarlane M, et al., "The Importance of SocioEconomic Versus Environmental Risk Factors for Reported Dengue Cases in Java, Indonesia," PLOS Neglected Tropical Diseases, vol. 10, no. 9, pp. 1-15, 2016.

[10] Li R, Xu L, Bjørnstad ON, Liu K, Song T, et al.,"Climate-driven variation in mosquito density predicts the spatiotemporal dynamics of dengue," Proceedings of the National Academy of Sciences, vol. 116, no. 9, pp. 3624-3629, 2019.

[11] Rather IA, Parray HA, Lone JB, Paek WK, Lim J, et al., "Prevention and Control Strategies to Counter Dengue Virus Infection," Frontiers in cellular and infection microbiology, vol. 7, no. 336, pp. 1-8, 2017.

[12] Elsinga J, van der Veen HT, Gerstenbluth I, Burgerhof JGM, Dijkstra A, et al. "Community participation in mosquito breeding site control: an interdisciplinary mixed methods study in Curaçao," Parasites \& vectors, vol. 10, no. 1, p. 434, 2017.

[13] WHO, Dengue Control, 2018. [Online]. Available: https://www.who.int/news-room/fact-sheets/detail/dengue-andsevere-dengue

[14] WHO, Chemical control, 2020. [Online]. Available: www.who.int/denguecontrol/control_strategies/chemical_control/en/

[15] Esu E., Lenhart A., Smith L., Horstick O., "Effectiveness of peridomestic space spraying with insecticide on dengue transmission; Systematic review," Tropical medicine \& international health, vol. 15, no. 5, pp. 619-31, 2010.

[16] WHO, Space spray application of insecticides for vector and public health pest control. Communicable Disease Control, Prevention and Eradication WHO Pesticide Evaluation Scheme (WHOPES), 2003.

[17] Reyes-Castro PA, Castro-Luque L., Díaz-Caravantes R., Walker KR, Hayden MH, et al., "Outdoor spatial spraying against dengue: A false sense of security among inhabitants of Hermosillo, Mexico," PLOS Neglected Tropical Diseases, vol. 11, no. 5, pp. 1-16, 2017.

[18] Nkya TE, Akhouayri I., Kisinza W., David J-P "Impact of environment on mosquito response to pyrethroid insecticides: Facts, evidences and prospects," Insect Biochemistry and Molecular Biology, vol. 43, no. 4, pp. 407-416, 2013.

[19] Karunaratne SH, Weeraratne TC, Perera MD, Surendran SN, "Insecticide resistance and, efficacy of space spraying and larviciding in the control of dengue vectors Aedes aegypti and Aedes albopictus in Sri Lanka," Pestic Biochem Physiol., vol. 107, no. 1, pp. 98-105, 2013.

[20] Teske ME, Thistle HW, Bonds JAS, "A Technical Review of MULV-Disp, a Recent Mosquito Ultra-Low Volume Pesticide Spray Dispersion Model, Journal of the American Mosquito Control Association, vol. 31, no. 3, pp. 262-270, 2015.

[21] Mayxay M., Cui W., Thammavong S., Khensakhou K., Vongxay V., et al., "Dengue in peri-urban Pak-Ngum district, Vientiane capital of Laos: a community survey on knowledge, attitudes and practices," BMC Public Health vol. 13, no. 434, pp. 1-8, 2013.

[22] Dhimal M., Aryal KK, Dhimal ML, Gautam I., Singh SP., et al., "Knowledge, attitude and practice regarding dengue fever among the healthy population of highland and lowland communities in central Nepal," PLoS One, vol. 9, no. 7, pp. e102028, 2014

[23] Saré D., Pérez D, Somé P-A, Kafando Y., Barro A., et al., "Community-based dengue control intervention in Ouagadougou: intervention theory and implementation fidelity," Global Health Research And Policy, vol. 3, no. 1, pp. 1-11, 2018. 
[24] Lin H., Liu T., Song T., Lin L., Xiao J., et al., "Community Involvement in Dengue Outbreak Control: An Integrated Rigorous Intervention Strategy," PLOS Neglected Tropical Diseases, vol. 10, no. 8, pp. 1-10, 2016.

[25] Hoffmann R., Lutz SU., "The health knowledge mechanism: evidence on the link between education and health lifestyle in the Philippines," The European Journal of Health Economics, vol. 20, no. 4, pp. 27-43, 2019.

[26] Usman HB, AlSahafi A., Abdulrashid O., Mandoura N., Al Sharif K, et al., "Effect of Health Education on Dengue Fever: A Comparison of Knowledge, Attitude, and Practices in Public and Private High School Children of Jeddah," Cureus, vol. 10, no. 12, p. e3809, 2018.

[27] Boonchutima S., Kachentawa K., Limpavithayakul M., Prachansri A., "Longitudinal study of Thai people media exposure, knowledge, and behavior on dengue fever prevention and control," Journal of Infection and Public Health, vol. 10, no. 6, pp. 836-841, 2017.

[28] Food and Environmental Hygiene Department, Hongkong. 2020. Vector Borne Diseases. 2020. [Online]. Available: https://www.fehd.gov.hk/english/pestcontrol/dengue_fever/index.html.

[29] El Moustaid F., Johnson LR, "Modeling Temperature Effects on Population Density of the Dengue Mosquito Aedes aegypti," Insects, vol. 10, no. 11, p. 393, 2019.

[30] Shen JC, Luo L., Li L, Jing QL, Ou CQ, et al., "The Impacts of Mosquito Density and Meteorological Factors on Dengue Fever Epidemics in Guangzhou, China, 2006-2014: a Time-series Analysis," Biomedical and Environmental Sciences, vol. 28, no. 5, pp. 321-329, 2015.

[31] Wijayanti SP, Octaviana D., Nurlaela S., "Mosquito Indices in Outdoor Spatial Spraying Treated Area, Banyumas Regency, Indonesia," IOP Conference Series: Earth and Environmental Science, vol. 255, p. 012033, 2019.

[32] Thammapalo S., Meksawi S., Chongsuvivatwong V., "Effectiveness of Space Spraying on the Transmission of Dengue/Dengue Hemorrhagic Fever (DF/DHF) in an Urban Area of Southern Thailand," Journal of Tropical Medicine, vol. 2012, no. 1, pp. 1-7, 2012. 